\title{
Study of Histopathology of the Tumour like Lesions and Tumours of the Oral Cavity
}

\author{
Dr. Yasmin Khan ${ }^{1}$, Dr. Shivaji D. Birare ${ }^{2}$ \\ ${ }^{1,2}$ GMC Latur, Maharashtra, India
}

\begin{abstract}
Aims: To study spectrum, clinical features and histopathology of different lesions of oral cavity. Settings and Design: This was a both retrospective and prospective study carried out in the department of pathology over a period of 5 years. Histopathological examination of a total of 70 cases of oral cavity lesions over a period of 5 years was done. Results: 42 (60\%) were tumours and 28 (40\%) were tumour like lesions. Most common tumour like lesion was pyogenic granuloma. Among tumours malignant tumours were most common. In benign tumours most common were hemangioma. Premalignant lesions included leukoplakia and erythroplakia. Amongst the malignant tumours most common were squamous cell carcinoma. Amongst the squamous cell carcinoma maximum were well differentiated. The peak incidence of tumour like lesions was in the age group of 20-40 and of tumours of oral cavity in $>60$ yrs age group. Male to female ratio in tumour like lesions was 1.8:1 while in tumours of oral cavity it was 1.6:1.Smoking was the most common habit both in tumours of the oral cavity and in tumour like lesions. Conclusions: Histopathology is an important tool in the diagnosis and management.
\end{abstract}

Keywords: histopathology, tumour like lesions, tumours,oral cavity

\section{Introduction}

Oral cancer is the most common cancer and constitutes a major health problem in developing countries, representing the leading cause of death. The incidence from the National Cancer Registry Project of the Indian Council of Medical Research confirmed the fact that oral cancer was indeed a common form of cancer in India .Although representing 2$4 \%$ of the malignancies in the West, this carcinoma accounts for almost $40 \%$ of all the cancers in the Indian subcontinent. ${ }^{1}$ They are of great significance, as they have a potential to jeopardize the health and longevity of the patient. ${ }^{2}$ Over $90 \%$ of these tumours are squamous cell carcinoma which arise from oral mucosal lining. ${ }^{3}$ Many oral carcinomas arise within regions that previously had premalignant lesion. The most common premalignant lesion seen in oral cavity is leukoplakia with associated dysplasia. ${ }^{4}$

In spite of ready accessibility of the oral cavity to direct examination these malignancies still are often undetected until a late stage and the survival rate for oral cancer has remained essentially unchanged over the past three decades. Proper management of the patient with the premalignant and malignant oral lesion starts with an accurate diagnosis. The current gold standard for diagnosis is histopathologic assessment of a tissue biopsy of suspicious lesion. ${ }^{5}$

\section{Material and Methods}

This was a both retrospective and prospective study carried out in the department of pathology over a period of 5 years (3yrears retrospective and 2 years prospective (October 2010 to October 2015). Histopathological examination formed the basis of study. A total of 70 cases over a period of 5 years were studies for histopathological examination.

\subsection{Selection of patient}

Patients with tumours or tumour like lesions of the oral cavity attending department of surgery and ENT and undergoing excision/operative procedure.

\subsection{Histopathological Study}

The specimen received in our histopathological section comprised of either excised specimen or biopsy specimen of suspected oral lesion. To obtain best result for histopathological assessment, the specimen were sliced immediately after resection/excision and then immersed in $10 \%$ formalin. The tissue bits were then processed by routine paraffin embedding techniques, 3-5 micrometer thick sections were cut and stained with hematoxylin and eosin stain.

\subsection{Statistical analysis used}

Data is presented by mean \pm standard deviation (SD).

\section{Results and Observations}

The present study was conducted from October 2010 to October 2015. A total of 70 patients who underwent oral biopsies were studied at a tertiary care hospital and following observations were made. An overall incidence of 'tumour like lesions', 'premalignant lesions' and 'tumours' of the oral cavity, related to age, gender and location along with histopathological findings were derived. Histopathological diagnoses of the 70 oral biopsies were as follows.

- 28 (40\%) were 'tumour-like-lesions'

- $5(7.1 \%)$ were 'premalignant lesions'

- 37 (52.85\%) were 'tumours'. 


\section{International Journal of Science and Research (IJSR) \\ ISSN (Online): 2319-7064}

Index Copernicus Value (2013): 6.14 | Impact Factor (2015): 6.391

Table 1: Tumour-like-lesions, premalignant lesions and tumours of the oral cavity

\begin{tabular}{|c|c|c|}
\hline Lesions & No. of Cases & Percentage (\%) \\
\hline Tumour-like-lesions & 28 & 40 \\
\hline Premalignant lesions & 5 & 7.1 \\
\hline Tumours & 37 & 52.8 \\
\hline Total & 70 & 100 \\
\hline
\end{tabular}

Tumour -like- lesions of the oral cavity

Amongst the 'tumour-like-lesions', we studied different lesions like pyogenic granuloma, mucocele, dermoid cyst, chronic inflammatory lesions and dentigerous cyst. Most common tumour like lesion was pyogenic granuloma accounting for 15 patients followed by chronic inflammatory lesions in 4 patients, dentigerous cyst in 4 patients, dermoid cyst in 3 patients and mucocele in 2 patients.

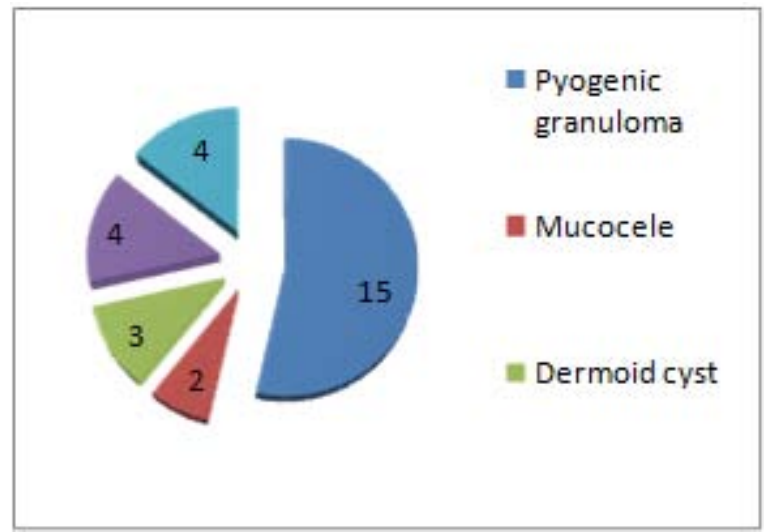

Figure 1: Distribution of 'tumour-like-lesions’ (N=28)

\section{Premalignant lesions}

'Premalignant lesions' included leukoplakia and erythroplakia. Leukoplakia was more common than erythroplakia.

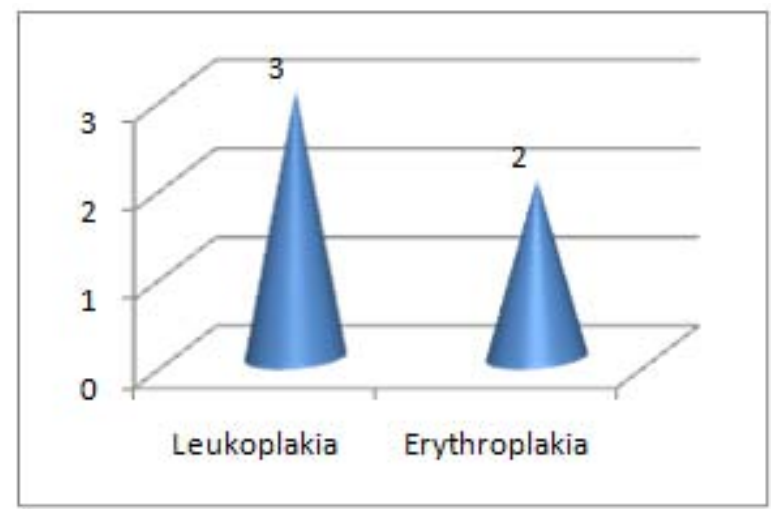

Figure 2: Distribution of premalignant lesions $(\mathrm{N}=05)$

\section{Tumours of the oral cavity}

Amongst the 'tumours' of the oral cavity we studied 'benign tumours' and 'malignant tumours'. Out of these, 'malignant tumours' were more common in 26 patients followed by 'benign tumours' in 11 patients.

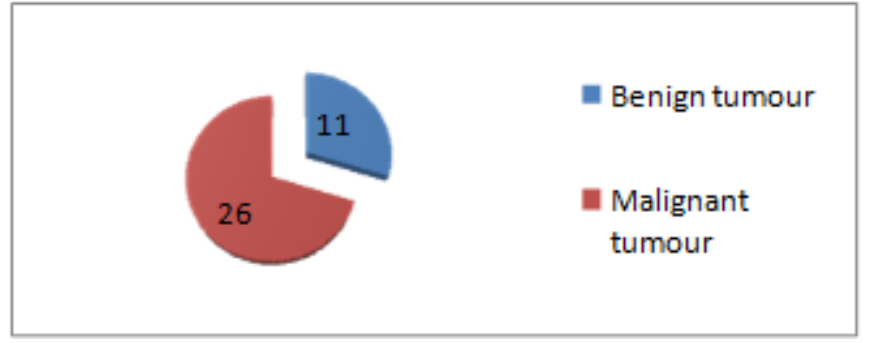

Figure 3: Distribution of ‘tumours' of oral cavity ( $\mathrm{N}=37$ )

\subsection{Age Distribution}

In seventy cases of oral biopsies studied $(n=70)$, the peak incidence of 'tumour-like-lesions' was in the age group of $20-40$ followed by $<20 \mathrm{yr}$ age group. Mean age for 'tumourlike-lesions' was $34.4 \pm 17$ yrs.

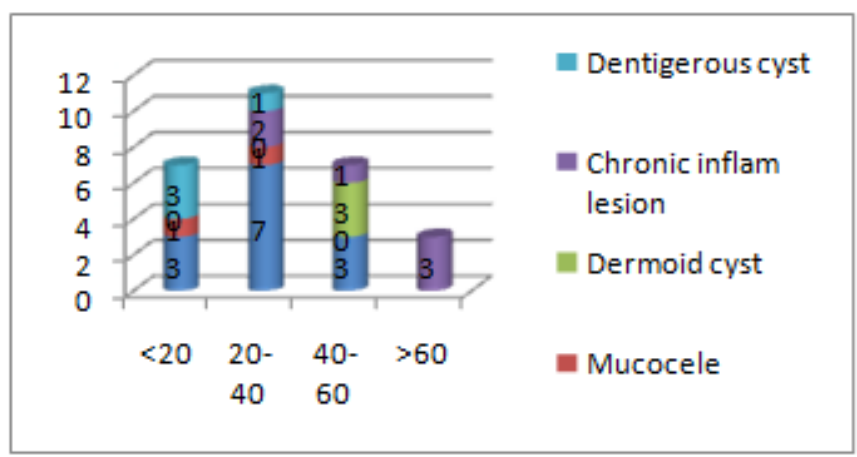

Figure 4: Age distribution of 'tumour-like-lesions' of oral cavity $(\mathrm{N}=28)$

Peak incidence of 'premalignant lesions' of oral cavity was in 40-60 yrs age group. Mean age for 'premalignant lesions' of oral cavity is $48 \pm 14 \mathrm{yrs}$.

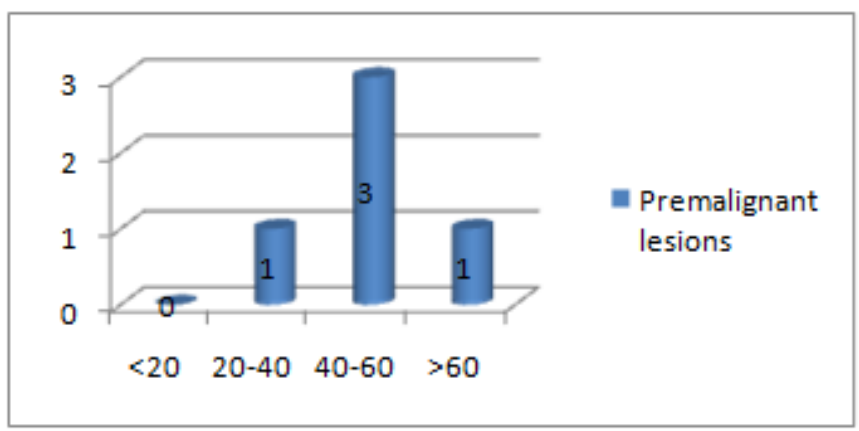

Figure 5: Age distribution of 'premalignant lesions' $(\mathrm{N}=5)$

Peak incidence of 'tumours' of oral cavity was in $>60$ yrs age group followed by 40-60yrs age group. Mean age for 'tumours' of oral cavity is $49 \pm 20 \mathrm{yrs}$. 


\section{International Journal of Science and Research (IJSR) \\ ISSN (Online): 2319-7064}

Index Copernicus Value (2013): 6.14 | Impact Factor (2015): 6.391

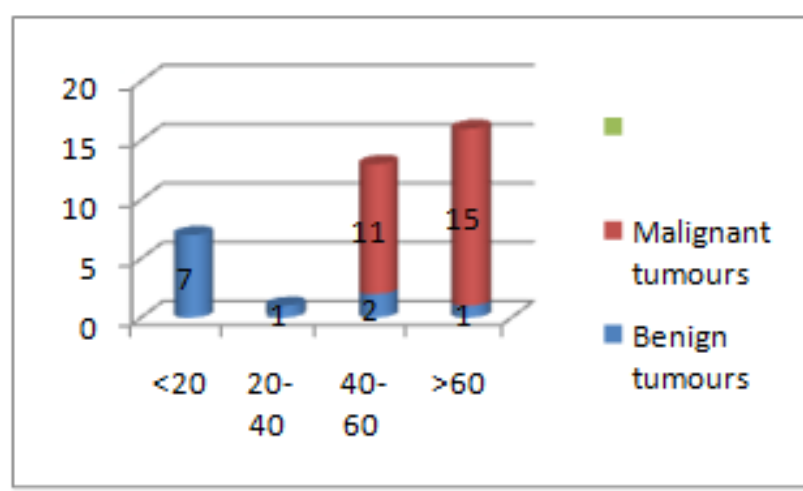

Figure 6: Age distribution of 'tumours' of oral cavity $(\mathrm{N}=37)$

\subsection{Sex Distribution}

In seventy cases of oral biopsies studied $(n=70)$, male to female ratio in 'tumour -like-lesions' was 1.8:1.

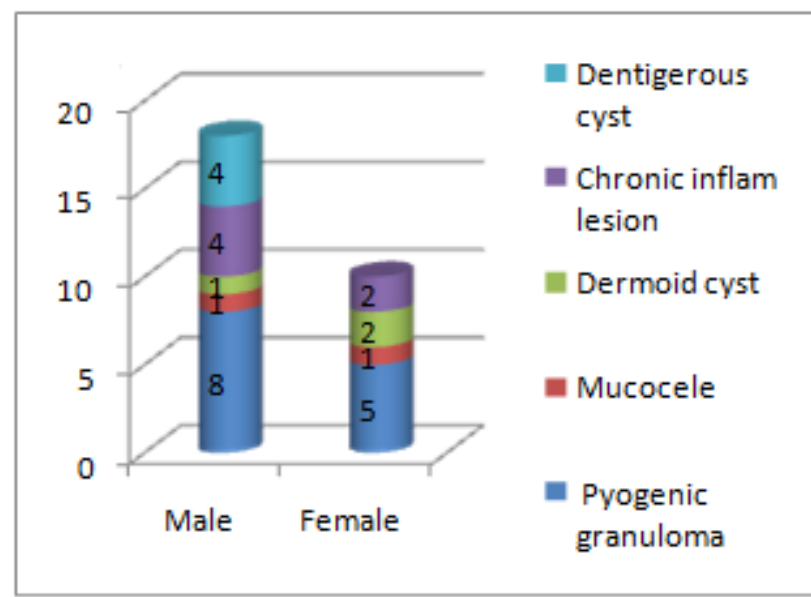

Figure 7: Sex distribution of 'tumour-like-lesions' of oral cavity $(\mathrm{N}=28)$

In seventy cases of oral biopsies studied ( $\mathrm{n}=70)$, male to female ratio in 'premalignant lesions' was 1.5:1.

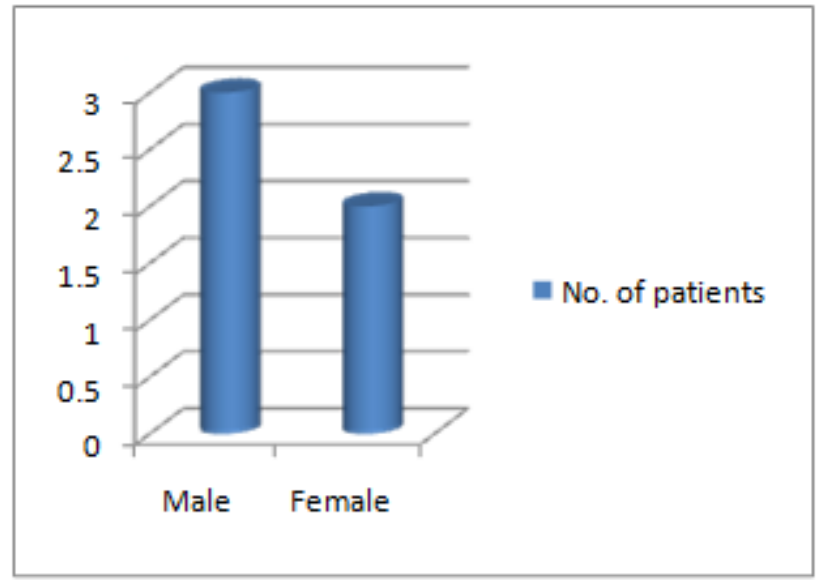

Figure 8: Sex distribution of 'premalignant lesions' $(\mathrm{N}=5)$

In seventy cases of oral biopsies studied $(n=70)$, male to female ratio in 'tumours' was 1.64:1.

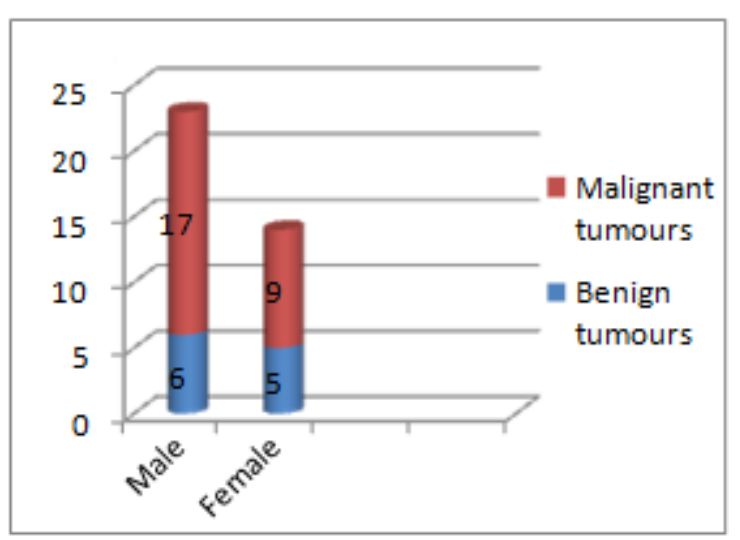

Figure 9: Sex distribution of 'tumours' of oral cavity $(\mathrm{N}=37)$

\subsection{Addiction}

Patients' habits were studied and were accordingly classified as those smoking, eating pan/ gutkha, drinking alcohol or those with combined addictive habits. Smoking was the most common habit followed by pan/gutka in all the conditions.

Table 2: Addiction ( $\mathrm{N}=70)$

\begin{tabular}{|c|c|c|c|c|}
\hline Addiction & $\begin{array}{c}\text { Tumour- } \\
\text { like-lesions }\end{array}$ & $\begin{array}{c}\text { Premalignant } \\
\text { lesions }\end{array}$ & $\begin{array}{c}\text { Tumours } \\
\text { (Benign } \\
\text { +malignant }\end{array}$ & Total \\
\hline Smoking (S) & 9 & 2 & 8 & 19 \\
\hline Alcohol (A) & 2 & & 3 & 5 \\
\hline Pan/gutkha(PG) & 6 & 2 & 7 & 15 \\
\hline Smoking + Alcohol & 1 & 1 & 3 & 5 \\
\hline $\begin{array}{c}\text { Smoking + } \\
\text { Pan/gutkha }\end{array}$ & 1 & & 8 & 9 \\
\hline $\begin{array}{c}\text { Smok+Alco+ } \\
\text { Pan/gutkha }\end{array}$ & 0 & & 1 & 1 \\
\hline No addiction & 9 & & 7 & 16 \\
\hline Total & 28 & 5 & 37 & 70 \\
\hline
\end{tabular}

\subsection{Site of lesion}

- 'Oral lesions' were most commonly found in buccal mucosa, gingiva and tongue.

- 'Tumour-like-lesions' were most commonly found in gingiva followed by buccal mucosa.

- 'Premalignant lesions' were all located on buccal mucosa.

- 'Tumours' of oral cavity were more commonly found in buccal mucosa followed by tongue.

Table 3: Site of lesion $(\mathrm{N}=70)$

\begin{tabular}{|c|c|c|c|c|}
\hline $\begin{array}{c}\text { Site of } \\
\text { lesion }\end{array}$ & $\begin{array}{c}\text { Tumour-like- } \\
\text { lesions }\end{array}$ & $\begin{array}{c}\text { Premalignant } \\
\text { lesions }\end{array}$ & $\begin{array}{c}\text { Tumours } \\
\text { (benign } \\
\text { +malignant }\end{array}$ & Total \\
\hline Buccal mucosa & 5 & 5 & 13 & 23 \\
\hline Tongue & 2 & & 9 & 11 \\
\hline Lip & 3 & & 7 & 10 \\
\hline Teeth & 4 & & 3 & 7 \\
\hline Hard palate & 2 & & 2 & 4 \\
\hline Gingiva & 12 & & 3 & 15 \\
\hline Total & 28 & 5 & 37 & 70 \\
\hline
\end{tabular}




\section{International Journal of Science and Research (IJSR) \\ ISSN (Online): 2319-7064}

Index Copernicus Value (2013): 6.14 | Impact Factor (2015): 6.391

\subsection{Histopathology of 'tumour-like-lesions'}

- In our study, 15 cases of Pyogenic granuloma were seen showing lobular pattern of capillary proliferation.

- 3 cases of Dermoid cyst were found in the study, with lining of stratified squamous epithelium with hair follicles.

- 2 cases of Mucocele were observed showing extravasated mucin and inflammatory infiltrate .

- In 4 cases of Dentigerous cyst, lining epithelium appears as uniformly thin and non-keratinized.

- 4 cases of Chronic inflammatory lesions were found in our study including Granuloma which showed epitheloid cells with lymphocytic infiltrate.

\subsection{Histopathology of 'premalignant lesions'}

Histopathology of 'premalignant lesion' revealed leukoplakia with hyperkeratosis in 1 patient, leukoplakia with moderate dysplasia in 1 patient, leukoplakia with severe dysplasia in 1 patient and erythroplakia with moderate dysplasia in 2 patients.

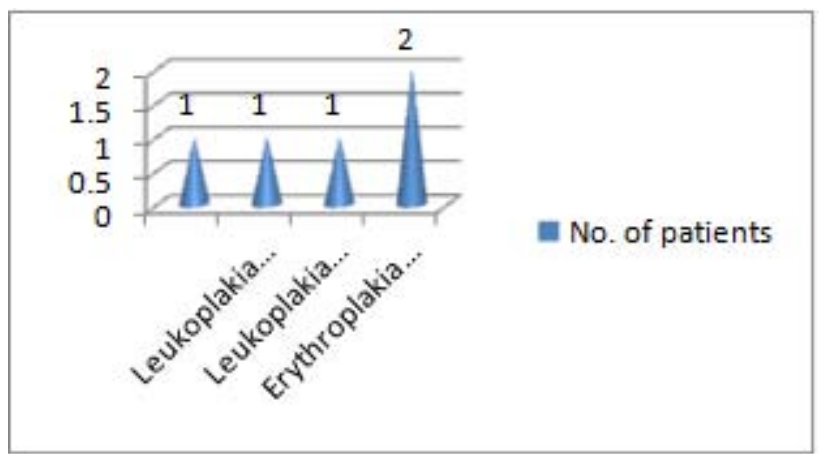

Figure 10: Histopathology of 'premalignant lesions' $(\mathrm{N}=5)$

\subsection{Histopathology of tumours Benign tumours}

In 'benign tumours' most common were hemangioma in 3 patients followed by adenomatoid odontogenic tumour in 2 patients. Other 'benign tumours' like lymphangioma, fibroma, granular cell tumour, schwannoma, neurofibroma, cementoblastoma each constituted 1 patient.

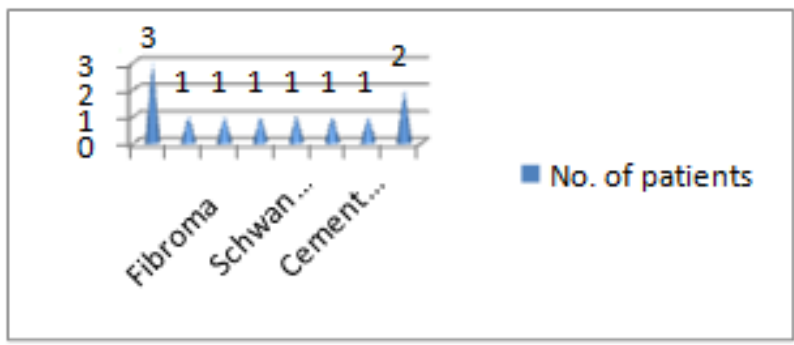

Figure 11 : Distribution of 'Benign tumours' $(\mathrm{N}=11)$

\section{Malignant tumours}

Amongst the 'malignant tumours' most common were 'squamous' cell carcinoma followed by 'verrucous' carcinoma and 'basal cell' carcinoma.

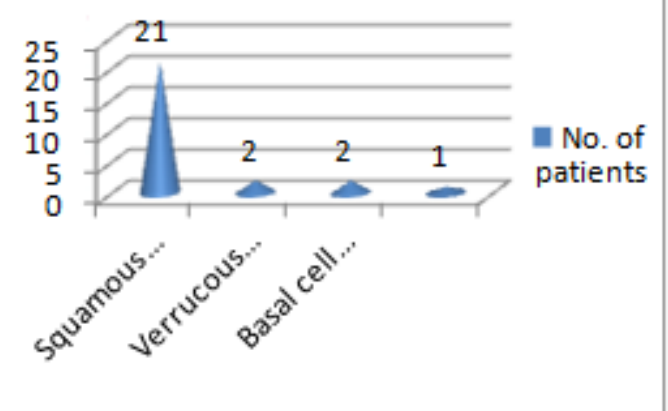

Figure 12: Distribution of malignant tumours $(\mathrm{N}=26)$

\subsection{Grading of malignant tumours}

Amongst the squamous cell carcinoma maximum were 'well differentiated' followed by 'moderately' and 'poorly differentiated'.

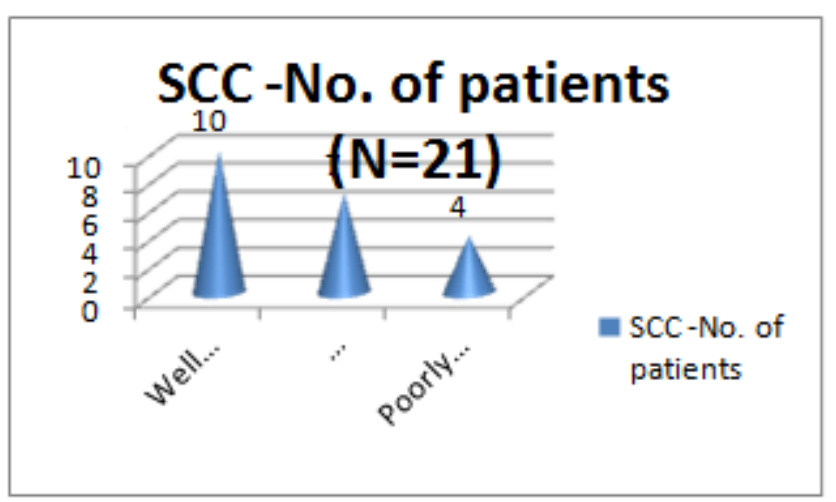

Figure 13: Differentiation of 'malignant tumours' (Squamous cell carcinoma) $(\mathrm{N}=21)$

\section{Discussion}

\subsection{Age}

In seventy cases of oral biopsies studied $(n=70)$, the peak incidence of tumour like lesions was in the age group of 2040 followed by $<20 \mathrm{yr}$ age group. Mean age for tumour like lesions was $25 \pm 5$ yrs. Peak incidence of tumours of oral cavity was in 40-60 age group followed by $>60$ yrs age group. Mean age for tumours of oral cavity was $62 \pm 5$ yrs. Present study is in concordance with Liu et al where highest incidence of premalignant lesions was found in 5th decade. Mehrotra $\mathrm{R}$ et al ${ }^{7}$ and Dietrich et al ${ }^{8}$ reported highest incidence of premalignant lesions in 6th decade, a decade later compared to the present study. Present study was in concordance with Mehrotra $\mathrm{R}$ et al ${ }^{7}$, Misra $\mathrm{V}$ et al ${ }^{2}$, Khandekar SP ${ }^{9}$ et al. A study done by Dragomir LP et al ${ }^{91}$ showed maximum incidences of malignant lesions in the 7th decade. Most of the studies found the maximum incidence of oral malignancies in people over 50 years of age in concordance with the present study

\subsection{Sex Distribution}

In seventy cases of oral biopsies studied $(n=70)$, male to female ratio in tumour like lesions was 1.8:1 while in tumours of oral cavity it was 1.6:1. The present study was in concordance with the findings of Dietrich et al ${ }^{8}$, Mishra et al

\section{Volume 5 Issue 4, April 2016}




\section{International Journal of Science and Research (IJSR) \\ ISSN (Online): 2319-7064}

Index Copernicus Value (2013): 6.14 | Impact Factor (2015): 6.391

11 and Liu et al ${ }^{6}$ in which premalignant lesions were more common in males. $60 \%$ versus $69 \%$ versus $53 \%$ versus $50.4 \%)$.In our study malignant lesions were more common in males (65.3\%)which was concordant with other studies like Durrazzo et al ${ }^{13}$ (68\%),Khandekar et al ${ }^{9}$ (61\%),Dias et al ${ }^{14}$ (80\%), Brandizzi et al ${ }^{15}$ (55\%) and Kruse et al ${ }^{16}$ (57\%). The fact that oral cancer affects many more men than women may be observed in all of the studies conducted in India as well as other countries. However, gender is not a risk factor per se in oral malignancies. ${ }^{87}$ The difference may be due to the high rate of tobacco and alcohol consumption among males. Tobacco addiction among males includes both chewing and smoking, in our society females usually do not indulge in smoking although a disturbing rising trend is noted. Males are also more likely to seek medical consultation early.

\subsection{Addiction}

Patients' habits were studied and were accordingly classified as those smoking,eating pan/gutkha ,drinking alcohol or those with combined addictive habits.Smoking was the most common habit followed by pan/gutka both in tumours of the oral cavity and in tumour like lesions

In a study by Iype et al ${ }^{17}, 56.4 \%$ of patients were habituated to either tobacco chewing, smoking or alcohol. In the study of Khandekar SP et al ${ }^{9}, 71.3 \%$ of patients were habituated to tobacco. $63.3 \%$ were habituated to tobacco in the form of cigarettes or beedis. In the study of Durazzo MD et al ${ }^{13}$ tobacco smoking was identified in $80.8 \%$ patients. Alcohol consumption history was retrieved in $56.6 \%$ patients. Dias et al ${ }^{14}$ reported history of tobacco use in $57.8 \%$ of patients with oral cancer. Alcohol consumers were $50 \%$ of the total number of cases. $43.8 \%$ of the patients were both alcoholics and smokers. In the study of Balaram et al ${ }^{70} 53 \%$ of patients were smokers. Drinkers of alcoholic beverages were $32 \%$. Pan chewing habit was found in 59\% men and $90 \%$ of women.

\subsection{Site of the lesion}

Oral lesions were most commonly found in buccal mucosa, gingiva and tongue. Tumours of oral cavity were more commonly found in buccal mucosa followed by tongue. Tumour like lesions were most commonly found in gingiva followed by buccal mucosa. In our study buccal mucosa was most common site of premalignant lesions (100\%) which was in concordance with the findings of Mishra M et al ${ }^{11}(52 \%)$, Lee $\mathrm{J} J$ et al(65\%) ${ }^{19}$,Misra $\mathrm{V}$ et $\mathrm{al}(55 \%)^{2}$ and was discordant with the study done by Liu $\mathrm{W}$ et $\mathrm{al}^{12}$ where tongue was the commonest site(51\%) for the premalignant lesions. In our study buccal mucosa was most common site(38\%)of malignant lesions which is concordant with the study of Ahluwalia et al(55\%) ${ }^{20}$ (2001), Sankaranarayanan R et al(50.4\%) ${ }^{21}$ (2005), Richard M et al(50.7\%) ${ }^{22}$ (2008). Our study was discordant with study done by Bhattacharjee et al 51 (2006) which showed anterior 2/3rd of the tongue (32.67\%) as the commonest site for malignant lesions. It is observed in various published literatures that anatomically more anterior parts (buccal mucosa, anterior 2/3 of the tongue, alveolus, lips, and base of tongue) are more frequently involved in oral malignancies. This could be due to the long duration of contact with the carcinogens in tobacco and alcohol

\subsection{Histopathological spectrum of premalignant lesions in our study}

Histopathology of premalignant lesion revealed leukoplakia with hyperkeratosis in 1 patient(20\%),leukoplakia with moderate dysplasia in 1 patient(20\%), , leukoplakia with severe dysplasia in 1 patient (20\%) and erythroplakia with moderate dysplasia in 2 patients(40\%), Lee J J et al ${ }^{19}$ (2006) analyzed one thousand and forty-six patients with OL, of which 408 cases were only epithelial hyperplasia and/or hyperkeratosis (EH). In 477 cases (45.6\%), epithelial dysplasias (ED) of various degrees were observed. Mild dysplasias were seen in 200 cases (19.12\%), moderate in 234 $(22.37 \%)$, and severe in $43(4.11 \%)$ cases. So our study was concordant with Lee $\mathrm{JJ}$ et al in terms of moderate dysplasia (20\% versus 22.35) and discordant in terms of severe dysplasia(4.11\% in Lee $\mathrm{JJ}$ et al verus $20 \%$ severe dysplasia in leukoplakia $40 \%$ severe dysplasia in erythroplakia in our study)

\subsection{Histopathological spectrum of malignant lesions}

In present study squamous cell carcinoma was most common malignant tumour $(80 \%)_{3}$ which was in concordance with Bhattacharjee et al(85\%) , Khandekar et al (72\%) ,Dias et al ${ }^{14}$ ( $\left.93 \%\right)$, Brandizzi D et al ${ }^{15}$ (91\%)Case of verrucous carcinoma showed well differentiated squamous epithelium with surface of the epithelium showing prominent parakeratin layer arranged in invaginating folds. The epithelial down growth was broad, having blunt rete pegs with a pushing margin infiltrating at the same level. The advancing edge of the squamous epithelium showed minimal cytologic atypia and mitotic activity. The lamina propria was composed of lymphoproliferative inflammatory cell infiltrate.

\subsection{Differentiation of tumour}

Amongst the squamous cell carcinoma maximum were well differentiated (47.61\%) followed by moderately (33.33\%) and poorly differentiated (19.04\%). Well differentiated squamous cell carcinomas showed sheets and nests of tumour cells with large hyperchromatic nuclei. The presence of individual cell keratinisation with keratin pearl formation was consistently seen in almost all the cases and are the prominent features of well differentiated. Moderately differentiated squamous cell carcinomas showed nuclear pleomorphism with decrease in individual cell keratinization. Poorly differentiated squamous cell carcinomas showed predominantly immature cells with numerous atypical mitosis with absence of individual cell keratinisation. The tumour cells showed lack of cohesiveness. In present study well differentiated SCC was most common histologic variety (47\%) and was in concordance with the study done by Patel $\operatorname{MM}(60 \%)^{24}$, Iype EM et al(52\%) ${ }^{17}$, Ahluwalia et al $(65 \%)^{20}$

Dragomir LP et al (2010) ${ }^{10}$ study however showed majority of the tumours of oral cavity as well differentiated SCC but showed an almost equal percentage of poorly differentiated squamous cell carcinomas. Whereas a study done by Jerjes $\mathrm{w}$ 


\section{International Journal of Science and Research (IJSR) \\ ISSN (Online): 2319-7064 \\ Index Copernicus Value (2013): 6.14 | Impact Factor (2015): 6.391}

et al ${ }^{89}$ showed majority of cases of modedrately differentiated squamous cell carcinoma.

\section{Conclusions}

Oral cavity lesions had vast spectrum ranging from tumour like lesions to benign and malignant tumours.Histopathology is an important tool in the diagnosis and management.

\section{References}

[1] Mehrotra R, Gupta A, Singh M and Ibrahim R. Application of cytology and molecular biology in diagnosing premalignant and malignant oral lesions. Molecular cancer 2006;5(11):476-498.

[2] Mishra V, Singh P A, Lal N A, Agarwal P, Singh P. Changing patterns of oral cavity lesions and personal habits over a decade: Hospital based record analysis from Allahabad. Indian journal of community medicine 2009;34(4):321-325.

[3] Neville B.W and Day T A. Oral cancer and precancerous lesions. Cancerjournal of clinicians 2002;52:195.

[4] Ramaesh T, Mendis B.R.R.N, Ratnatunga N, Thattil R.O. Diagnosis of oral premalignant and malignant lesions using cytomorphometry.Odonto-Stomatologic Tropicale1999;12:124-28

[5] Poh C. F, Samsung Ng, Berean K, Williams P.M, Rosin M P, Leie Zhang L. Biopsy and Histopathologic Diagnosis of Oral Premalignant and Malignant Lesions. JCDA 2008;74(3)283-88.

[6] Liu W, Wang YF, Zhou HW, Shi P, Zhou ZT, and Tang GY. Malignant transfornmation of oral leukoplakia: a retrospective cohort study of 218 Chinese patients. Cancer 2010;10:685

[7] Mehrotra R, Singh M, Kumar D, Pandey AN, Gupta RK, Sinha US. Age specific incidence rate and pathological spectrum of oral cancer in Allahabad. Indian Journal of Medical Sciences 2003; 57(9):400-404.

[8] Dietrich AT, Reicharta PA, Scheifelea C. Clinical risk factors of oral leukoplakia in a representative sample of the US population. Oral Oncology 2004;40:158-163.

[9] Kandekar SP, Bagdey PS, Tiwari RR. Oral cancer and some epidemiological factors: A Hospital based study. Indian Journal of Community Medicine 2006;31(3):15759.

[10]Dragomir LP et al Clinical, epidemiological and histopathological Prognostic Factors in Oral Squamous Carcinoma. Current Health Sciences Journal 2010; 36(4):1-9

[11] Mishra M, Mohanty J, Sengupta S, Tripathy S. Epidemiological and clinicopathological study of oral leukoplakia. Indian Journal ofDermatology Venereology and Leprosy 2005;71(3):161-65.

[12] Liu W, Wang YF, Zhou HW, Shi P, Zhou ZT, and Tang GY. Malignant transfornmation of oral leukoplakia: a retrospective cohort study of 218 Chinese patients. Cancer 2010;10:685

[13] Durazzo MD, Araujo CEN, Brandao Neto JS, Potenza AS, Costa P et al. Clinical and epidemiological features of oral cancer in a medical school teaching hospital from 1994 to 2002: increasing incidence in women, predominance of advanced local disease, and low incidence of neck metastases. Clinics 2005;60(4):293-8

[14]Dias GS, Almeida AP. A histological and clinical study on oral cancer: Descriptive analyses of 365 cases. Med Oral Patol Oral Cir Bucal 2007;12(7):474-8.

[15]Brandizzi D, Gandolfo M, Velazco ML, Cabrini RL, Lanfranchi HE. Clinical features and evolution of oral cancer: A study of 274 cases in Buenos Aires, Argentina. Med Oral Patol Oral Cir Bucal 2008;13(9):544-8.

[16] Kruse A L, Bredell M, and Grätz K W. Oral squamous cell carcinoma in non-smoking and non-drinking patients. Head Neck Oncol 2010; 2(24):1-8

[17] Iype EM, Pandey M, Mathew A, Thomas G, Sebastian P, Nair MK. Oral cancer among patients under the age of 35 years. J postgrad Med 2001;47(3):171-6

[18] Balaram Prabha, Sridhar H, Rajkumar T, Vaccarella S, Herrero R, Nandakumar A. et al. Oral cancer in Southern India: the influence of smoking, drinking, pan chewing and oral hygiene. Int J Cancer 2002;98: 440-45

[19] Lee JJ, Hung HC, Cheng SJ, et al. Carcinoma and dysplasia in oral leukoplakias in Taiwan: Prevalence and risk factors. Oral Surgery, OralMedicine, Oral Pathology, Oral Radiology and Endodontology 2006;101(2):472-480.

[20] Ahluwalia $\mathrm{H}$, et al. Spectrum of head and neck cancers at Allahabad. IndianJournal of Otolaryngology and Head and Neck Surgery 2001;53(1):16-21.

[21] Sankaranarayana R, et al. Effect of screening on oral cancer mortality in Kerala, India: A cluster randomised controlled trial. Lancet 2005;365:1927-33.

[22] Richard M, Kunnambath R, Risto S. et al. Role of tobacco smoking, chewing and alcohol drinking in the risk of oral cancer in Trivandrum, India: A nested casecontrol design using incident cancer cases. Oral oncology 2008;44:446-454.

[23]Bhattacharjee A, Chakraborty A, Purkaystha P. Prevalence of head and neck cancers in North East - An institutional study. Indian J Otolaryngol HeadNeck Surg 2006;58(1):15-19

[24] Patel MM and Pandya AN. Relationship of oral cancer with age, sex, site distribution and habits. Indian $J$ Pathol Microbiol 2004;47(2):195-197.

[25] Jerjes W et al. Clinicopathological parameters, recurrence, locoregional and distant metastasis in 115 T1-T2 oral squamous cell carcinoma patients. HeadNeck Oncol 2010;2(9):1-11.

\section{Author Profile}

Dr. Yasmin Khan did MBBS from GMC Bhopal and is $3^{\text {rd }}$ yr post graduate student MD Pathology from GMC Latur. 